New Zealand Journal of Industrial Relations, 1981,6 57-65

\title{
Union involvement in health issues: The VIC RAIL Asbestos Dispute
}

\author{
John Benson*
}

This article examines the VIC RAIL Asbestos Dispute which took place in Victoria, Australia during 1977-78. The dispute was significant in that the general awareness generated by the union campaign and the publicity given by the media, was instrumental in securing workers' demands. It also illustrated the need for workers and union officials to carefully assess the dangers present on the job; a task that cannot be left solely to management or the government.

\section{Introduction}

In Australia, as in most western countries, the issues of occupational health and safety have been sadly neglected. The reasons for this are varied but in general stem from the feeling that injuries were accidents of fate ${ }^{1}$ and this, coupled with inadequate statistics, led to a tacit acceptance of the problem. The effect has been for our society to view industrial health in terms of the ability of employees to continue in the production process (Dreitzel, 1971), with the result that employers only considered safeguards when the viability of the business undertaking was seriously threatened. Unions also had been preoccupied with economic concerns and regarded safety issues as peripheral to their traditional concern with wages and conditions. When safety issues did arise the emphasis was on "dirt money" or compensation, rather than the prevention or reduction of risk. Given the attitude of employers and unions towards occupational health and safety, governments saw fit only to enact the minimum of legislation. This legislation, often relying on self regulation, proved ineffective, for not only were the provisions inadequate and inspection facilities virtually non-existent, but there was a distinct lack of formal provisions for worker education on the dangers inherent in the industrial environment. Occupational health was thus seen primarily as the responsibility of the individual employee.

In recent years the situation has changed, albeit slowly. Governments are now recognising the need to have more than an assortment of Factory Acts on their legislative records, with some Australian states having passed detailed legislation, for example the 1972 South Australian Industrial Safety, Health and Welfare Act. Individual unions have also begun to develop health and safety policies with the Australian Council of Trade Unions (ACTU) in 1979 adopting its first policy on occupational health. The impetus for such changes is varied, but issues such as the Victorian Railways (VIC RAIL) Blue Train Asbestos Dispute of 1977-1978 have been instrumental in generating awareness of the dangers of our industrial working environment and the need for employee protection through worker involvement and legal regulation.

* Lecturer in Industrial Relations, Gippsland Institute of Advanced Education, Churchill, Victoria, Australia 3842. I am indebted to the anonymous referees of this journal and to my colleagues at the Department of Management, Lanchester Polytechnic, Coventry, United Kingdom for their helpful suggestions and criticism.

1 For example:

any chain of events, however well planned, may include some unplanned event. It may be the result of some nonadjustive act on the part of an individual, some malfunction of a machine, or some situation in which we are unprepared for a contingency. (Gilmer, 1971, p. 515) 
The VIC RAIL Asbestos Dispute was significant for two reasons. First, the general awareness generated by the union campaign and the publicity given by the media was instrumental in workers' demands, both in VIC RAIL and other organisations, for protection as well as removal and substitution of asbestos products, being met. Second, it illustrated the need for workers and union officials to carefully assess the dangers present on the job; a task that cannot be left solely in the hands of management or the government. The unfortunate aspect of this dispute was that it was avoidable, as evidence of asbestos related illnesses was available at the time of the train's construction.

This paper will examine this dispute and attempt to locate it in the context of these wider considerations. The first section briefly discusses the dangers of asbestos and the development of asbestos standards. The second section examines the dispute in some detail paying particular attention to the positions adopted by VIC RAIL, the Victorian Government and the unions involved, namely the Australian Railways Union (ARU), the Amalgamated Metal Workers and Shipwrights Union (AMWSU) and the Electrical Trades Union (ETU). The final section provides a brief analysis of the roles of the Industrial Hygiene Division of the Victoria Health Commission (IHD), the Australian Conciliation and Arbitration Commission (ACAC) and the significance of this dispute in subsequent industrial health matters.

\section{Asbestos: Dangers and Standards}

Asbestos is the name given to a group of naturally occurring mineral silicates that crystallize into silky fibres between layers of rock. The very properties that make it useful: low cost, strength, stability in acids or alkalis and heat resistance, also underlie the dangerous nature of the substance. These properties have led to its widespread use ${ }^{2}$ but it is this virtual indestructible nature of asbestos that has caused severe medical problems arising whenever it is inhaled or ingested. This is aptly summarised by Gillespie (undated p. 7) as "miracle fibre-killer dust".

Asbestos is now recognised medically as representing a severe health threat (International Agency for Research on Cancer, 1977; Morgan, 1975). However knowledge of the hazards of asbestos is not new:

The first case of asbestosis was diagnosed by an English doctor back in 1900, less

than 20 years after the asbestos industry had been established. Other cases were noted in Europe and North America in the ensuing years, so that by 1917 Canadian and United States insurance companies were no longer insuring asbestos workers because of the recognised health hazards associated with the industry. (Gillespie, 1980, p. 32)

What is recent, is the public concern over the dangers of asbestos. This highlights the fact that scientific knowledge alone will afford little protection to those at risk with the onus falling on "others" to prove that a substance is dangerous. Companies with a vested interest in the mining of asbestos and the manufacture of asbestos-related products cannot be relied upon to provide self-critical information. In the same way, neither can those bodies that make use of asbestos products. Successive governments, in Australia, both state and federal, have for years been aware of the health problems associated with asbestos but have done little more than legislate for voluntary regulation. In Victoria, government authorities like VIC RAIL and the State Electricity Commission of Victoria (SECV) have made extensive use of asbestos products and consequently would be faced with huge outlays if Parliament enacted comprehensive legislation. Thus, without access to the necessary information and the support of government, the task of generating public awareness is extremely difficult.

2 It has been calculated that asbestos in its various forms has over 3,000 uses. Some common uses are: sheet building materials, car brake linings and clutch plates, vinyl floor tiles, fireproof building insulation, lagging for pipes, and sprayed insulation for fire and sound proofing in buildings and also in trains.
(See: Rosato, 1959) 
Medical problems directly associated with asbestos can be broken into asbestosis; a scarring of the lungs, and cancer, including mesothelioma; a rare form of lung and stomach cancer. Asbestosis was clearly established as an occupational disease by 1930 as a result of an investigation by members of the British Factory Inspectorate (Merwether and Price, 1930). Following this a number of studies began to link cancer with asbestos, which not only established "asbestos caused lung cancer" (Doll, 1955, pp. 81-86), but also revealed that low levels of exposure were significant and thus established the non-occupational hazards of asbestos (Wagner, 1960, pp. 260-271). ${ }^{3}$ Whilst all forms of asbestos are linked with both asbestosis and cancer it does appear that crocidolite or blue asbestos is the most dangerous form (National Health and Medical Research Council, undated). An unfortunate aspect of asbestos-related illnesses is that apart from being incurable, signs of the illness often do not appear for many years. As a consequence medical complaints are not always related to earlier asbestos exposure thus making more difficult preventative measures or at least the awareness of the need for such measures.

What then constitutes an acceptable level of airborne asbestos fibres under which no protective action need be taken? The World Health Organisation has stated that there exists no safe level of exposure to asbestos dust (Workers' Health Centre, undated), but the acceptance of a standard will be based on two factors, namely; the measurement of the risk to workers exposed to asbestos, and what constitutes an acceptable risk. As Lowrance (1976, pp. 75-76) points out, the former "is an empirical, scientific activity" whilst the latter constitutes a "normative, political activity". Thus the establishment of a standard will not depend solely on medical or scientific evidence but on the whole range of activities operative in the political process.

In 1969 the British Government adopted a chrysotile (white asbestos) standard of 2 fibres $/ \mathrm{ml}$. That is the number of airborne asbestos fibres per millilitre of air must not exceed two without protective action taking place. ${ }^{4}$ Many countries have since adopted this standard as the level of acceptable risk they are prepared to assume. Australia was slow to respond with Queensland in 1971 becoming the first state to introduce some asbestos regulations. This legislation required notification of asbestos use, ventilation, cleanliness and protective clothing, although no specific dust limit was set. South Australia followed in 1976 with a limit of 4 fibres/ml, with New South Wales adopting a limit of 2 fibres $/ \mathrm{ml}$, in 1978. (Gunningham, 1978, pp. 46-49) At the time the VIC RAIL dispute arose, Victoria did not have asbestos regulations, nor were there any proposed. Queensland and South Australia by this stage had banned the use of crocidolite (blue asbestos).

In the final analysis it will be those working with asbestos who will decide the level of tolerable risk. This is illustrated dramatically in the case of British Rail. For blue asbestos the British Factory Inspectorate standard was 0.2 fibres $/ \mathrm{ml}$, however British Rail adopted in 1967, after considerable union pressure, the more stringent standard of 0.05 fibres $/ \mathrm{ml}$.

The Dispute: Background, Issues and Their Resolution

VIC RAIL, as with many other large industrial undertakings, has made extensive use of asbestos and asbestos-related products. Of particular concern in this dispute was the use of asbestos as lining and insulation in what are known as the Harris (Blue) trains.

From 1957 to 1962 VIC RAIL imported about 90 Harris carriages from the United Kingdom and assembled another 130 at their Newport workshops. Blue asbestos in these carriages was used as insulation, being sprayed on the inside of the exterior walls from floor to ceiling. Carriages assembled after 1962 did not contain asbestos insulation as the Health Department had warned VIC RAIL that it could be dangerous. ${ }^{5}$ This matter was first

3 Wagner found that people not working in the mines but living in close proximity also contracted mesothelioma.

4 This means based on current medical evidence that 50 years exposure to this quantity will produce the earliest signs of asbestosis in 1 percent of the workforce.

5 Statements attributed to the General Manager - VIC RAIL (The Age, 1 February, 1978, p. 5) and the Victorian Health Minister (The Herald, 2 February, 1978, p. 5). 
raised in 1957 and arrangements were made for all employees involved with asbestos to be $\mathrm{X}$-rayed and medically examined. In fact VIC RAIL was alerted to the problems of asbestos as early as 1953 (Peacock, 1978, p. 127), although at this stage neither the workers nor the unions were notified.

The medical examinations of the 70 men involved in the construction of the Harris trains were conducted by Dr Bryan Gandevia of the Royal Melbourne Hospital. On the basis of this work he concluded that the risks of asbestosis were mild. In relation to the 1977-78 dispute he qualified his earlier findings by stating:

The different problem, of a relationship of mesothelioma to crocidolite, was not then accepted. and

In the light of later information I would regard the exposure to blue asbestos as probably carrying a significant risk of mesathelioma. ${ }^{6}$

Thus whilst VIC RAIL may not have realised in 1957-58 the precise dangers of exposure to asbestos, a number of subsequent events should have alerted VIC RAIL to these problems and to develop appropriate policies. These events include:

(a) improved knowledge of asbestos related diseases, especially mesothelioma;

(b) the publicity surrounding the closing down of the Wittenoom Blue Asbestos mine in Western Australia in 1966;

(c) the official diagnosis that the death of two VIC RAIL employees was due to asbestosis. (Another employee has retired due to the effects of asbestosis and a fourth employee has developed mesothelioma.) All these workers were employed on the assembly of the Harris trains and workers' compensation was awarded to two of them. (Gillespie, undated, p. 48); and

(d) the banning of the use of blue asbestos by British Rail in 1967. (Ten years later, in 1977, British Rail announced that over the next four years it would spend some 30 million pounds removing asbestos from all trains built prior to the ban. ${ }^{7}$ )

In 1971 VIC RAIL commenced a programme of remodelling the Harris carriages for use in the Melbourne Underground Loop. The operation, carried out in the Bendigo workshops, involved removing partitions and cutting doors in both ends of the carriages. The workers, unaware of the dangers, had negotiated a special "dirt allowance" and apart from the occasional use of a cartridge type respirator were working unprotected. Six years passed until in June 1977 a dispute arose concerning this special allowance; it appeared VIC RAIL wanted to cut the allowance. The local shop stewards contacted their union, the ARU, and an organiser was dispatched to the Bendigo workshops. The official reported back that the men were working in "a most unsatifactory situation" in what appeared to be asbestos dust. The union responded by placing immediate bans on further conversion work and reporting the problem to the Industrial Hygiene Division of the Victorian Health Commission. A subsequent union instigated analysis confirmed that the insulation was blue asbestos, although it was several weeks later that the IHD accompanied by a VIC RAIL medical officer went to Bendigo to carry out investigations. The ARU, perhaps naively, expected a quick response; however this was not the case. It would not be until February 1978 that the test results were known.

During the remaining part of 1977 a stalemate developed. The bans remained in force, the ARU made at least two requests to VIC RAIL for the results of IHD tests but the reply was the same; "they were not yet available". The workers at Bendigo also made repeated requests at the local level, as one worker put it:

We've been treated with arrogance and ignorance. When I asked the Manager about the results, first he hadn't heard anything. Then he said, 'Oh what do you want to know for?' and then we had the chap up from town, from the Safety First

6 Letter from Professor Gandevia to Mr J Frazer, 6 March 1978.

7 The Age, 1 February, 1978, p. 5. 
Committee, and I asked him the same question and he said, 'What do you want to know for? If you know the answer, what are you going to do about it?' and we've been treated badly all along. (Peacock, 1978, p. 125)

The positions of both VIC RAIL and the unions were clear. The ARU concerned about its members' safety adopted a firm position; one which left little room to negotiate. Workers' safety was paramount and they were prepared to engage in lengthy industrial action to achieve this end. VIC RAIL on the other hand seemed convinced there was no problem and strongly opposed the union's claims.

In 1978 the issue came to a head when on 31 January the Australian Broadcasting Commission ( $\mathrm{ABC}$ ) programme Broadband concluded its series on asbestos with an examination of the "Melbourne Blue Trains" dispute. The programme not only stated the findings of the IHD, that VIC RAIL employees at the Bendigo workshops had been exposed to levels of asbestos contamination as high as 11 fibres/ml, which is some 220 times the British Rail standard, but that all those who worked or travelled on Harris trains could "well be exposed to lethal doses of the asbestos dust" (Peacock, 1978, p. 119). This publicity had two effects: the asbestos issue was brought out into the open, and it forced VIC RAIL to release the long awaited IHD report on the Bendigo workshops' asbestos problem.

The following day the Age ran an article titled "Cancer risk in blue train lining"8 based on the Broadband programme and the ARU promptly extended the ban to include all maintenance work involving asbestos at the Newport and Jolimont workshops. The debate had shifted to public safety with the Victorian Health Minister "claiming there was no danger to passengers".9 In reply to the Age's article Dr David Goddard and Mrs Janet Sowden of the IHD, who carried out the tests at Bendigo stated:

From a theoretical point of view it can be maintained that some risk always remains to exposure to a substance that produces cancer, however small this exposure might be; but from the practical point of view, the risk ceases to be of significance when it becomes sufficiently small and would normally then be referred to as being nonexistent. ${ }^{10}$

This was a surprising comment, given a major article appeared the same day in the Age titled "No-risk claim rejected" which quoted Dr Eric Longley of the New South Wales Public Health Commission and the Dust Diseases Board as saying that "Melbourne train passengers were risking asbestos contamination". It further raised the point of whether British Rail was spending 30 million pounds to remove a purely theoretical and nonexistent danger.

The ETU and the AMWSU followed the ARU and placed bans on all maintenance work on the Harris blue trains. Unless certain safeguards were implemented by VIC. RAIL the suburban rail system would be severely disrupted. VIC RAIL responded quickly and on 8 February received a deputation from the unions concerned. After general discussion on the problems of asbestos and delays on acting on the IHD report ${ }^{11}$ agreement was reached on the formation of a tripartite committee comprising the unions, VIC RAIL and the Department of Health to investigate the "more dangerous" aspects of asbestos work. In return the unions undertook to give VIC RAIL a quick reply to the question of lifting the bans on work that did not involve the disturbance of asbestos. ${ }^{12}$

Further tests were then carried out, under union supervision at the Jolimont workshops, where recorded levels of asbestos dust ranged from 0.003 to 0.63 fibres $/ \mathrm{ml} .{ }^{13}$ These levels could be significantly reduced by the use of vacuum cleaners. In view of this and the mini-

8 The Age, 1 February, 1978, p. 5.

9 The Age, 2 February, 1978, p. 5.

10 The Age, 3 February, 1978 , p. 8.

11 VIC RAIL had received this report (dated 13 July 1977) in July 1977, although it was not made available to the unions for over six months.

12 Asbestos Deputation Minutes, 8 February 1978.

13 Asbestos: How the Dispute Started, ARU Gazette, April 1978, p. 3. 
mum time staff were exposed to the levels, the IHD recommended that respiratory equipment was only necessary when carrying out certain tasks. The unions rejected these recommendations maintaining that the only acceptable standard was nil exposure, and that every worker was to have maximum protection regardless of the IHD recommendations. This position was understandable for not only were the unions concerned with the health of their members but they also felt sure that political pressure was being brought to bear on the IHD.

Throughout the duration of the dispute the responsible minister remained silent. When the matter was first raised in Parliament, Mr Roper, for the Opposition, addressing the Minister of Transport stated that he felt the advice given to him by the Minister of Health had let VIC RAIL down (Victorian Parliamentary Proceedings, 1978, pp. 571-572). Indeed VIC RAIL had stopped using blue asbestos in the Harris carriages "in the early 1960 s after warnings that it could be dangerous." 14 Why then the renewed resistance to the union's claim? The secretary of the ARU, Mr Jim Frazer, felt that VIC RAIL was being wrongly advised by the Department of Health, with Gillespie (undated, p. 51) concluding that the reason behind this was that pressure was applied to the IHD to make recommendations that would not involve VIC RAIL spending considerable amounts of money.

Again a stalemate had developed. Negotiations between the parties continued, however few concessions were granted by either VIC RAIL or the unions. The unions concerned about the advice from the IHD sought advice from the Workers' Health Resource Centre. This group, which has a decidedly different outlook from the IHD agreed with the position adopted by the unions that no safe level of exposure existed.

VIC RAIL on the other hand, wishing for a quick resolution to the problems notified the ACAC of the existence of a dispute. On 17 March, 1978 a meeting between VIC RAIL and the unions agreed to a test run of protective equipment for a period of one week. This trial however was to be conducted on the "red and silver trains". Before this test period was over the dispute came before the ACAC. A number of meetings between VIC RAIL and the unions followed, resulting in a compulsory conference of all parties before the ACAC on 31 March, 1978 at the Jolimont workshops. The unions expressed concern that Commissioner Walker, along with officials of VIC RAIL, were putting considerable pressure on union officials to lift the bans.

During this conference the unions presented a 15-point proposal put forward by the Jolimont Shop Committee.

i. A special change room be set aside for the gear to be worn and that no bans be lifted until this is provided.

ii. The special gear be worn by all working on blue trains.

iii. Supervisors who inspect or check work on blue trains also be required to wear special gear while in, on, or under, blue trains.

iv. That more powerful compressors or air lines be provided than were used on Friday, 3 March.

v. That no man be disadvantaged in conditions or employment if he finds it impossible to work wearing the gear.

vi. That nobody be transferred out of the inspection shop who cannot work in special gear unless he voluntarily agrees.

vii. Taking into account those who are unable to work in special gear a roster be drawn up amongst all others so that everyone has an equal share of working on blue trains.

viii. That each employee be issued with his own personal protective gear and that there is no inter-changeability of such gear.

ix. That the length of time that the average person can wear such gear and continue to work comfortably be assessed and no one work longer without a breather.

14 The Age, 1 February, 1978, p. 5. 
$x$. That the unions negotiate an allowance for those who have to work wearing such protective gear.

xi. That we recommend to a mass meeting that this agreement, in principle, to lift bans on blue trains, apply only to the inspection shop, provided safeguards and conditions are met, and not to the other shops until work in these shops on blue trains is metered and evaluated.

xii. That all shops continue to ban any form of machining on asbestos.

xiii. That the department take rapid steps to phase out the use of any brake-blocks that contain asbestos.

xiv. That the AMWSU policy in regard to the phasing out of all asbestos in five years be endorsed.

xv. We decide to reserve the right to reimpose bans after a trial period if we believe that it is impossible to work safely in the vicinity of asbestos or asbestos dust. ${ }^{15}$

In addition, they produced a letter from Professor Gandevia ${ }^{16}$ who suggested that a comprehensive medical examination of all men who have worked on the blue trains should be undertaken. ${ }^{17}$ After a full day of discussions, including a visit to a factory that manufactured respirators and protective clothing, VIC RAIL made a number of proposals in response to the demands of the Jolimont Shop Committee as well as agreeing in principle to the setting up of an advisory committee to undertake further examinations as proposed by Professor Gandevia. Union officials then gave Commissioner Walker an assurance that they would recommend the removal of all bans provided VIC RAIL met the first proposal of the shop committee's 15 requests, namely that a change room with showers was immediately provided. Upon receiving this assurance the settlement was put to a mass meeting at the Jolimont workshop on 5 April where it was agreed to lift all bans. Workers at Bendigo and Newport followed suit.

\section{Significance and Implications of the Dispute}

The foregoing discussion concentrated on the positions adopted by VIC RAIL and the unions throughout the dispute and discussed the processes that led to a resumption of work. Agreement between the parties was reached, although the problem of the removal of asbestos from the Harris carriages has yet to be resolved. Throughout the dispute the unions in particular questioned the usefulness of the IHD in the resolution of the problem. They believed it acted as a manipulable instrument of government: the effect was to underestimate and to disregard the evidence on the dangers of asbestos. This seems a remarkable turn-about as in 1956 the IHD declared asbestos dangerous. This followed tests by the late Dr Thomas of the IHD on 260 asbestos workers and prompted the IHD to draft a set of regulations to not only control its use and manufacture but to provide safeguards including protective equipment, dust extraction systems and regular medical examinations of those employees working with asbestos (Peacock, 1978, pp. 127-128). Now, more than 20 years later, there does not appear to be any record of these proposed regulations. During the Arbitration hearings the IHD's recommendation that protection on some tasks was unnecessary due to the short exposure time was criticised by both the unions and the Commission. This further reinforced the union's stance that the IHD was primarily concerned with the resumption of work rather than the health of the workers.

The IHD also played a major role in the subsequent drafting of the Victorian Asbestos Regulations. It is interesting to note that they recommended the British Occupational Hygiene Society's (BOHS) standard of 2 fibres/ml, even though this standard was over ten years old. Once again the unions were critical of the IHD as they felt that this body was the only group "with sufficient political and scientific prestige to lower the standard". (Gilles-

15 ARU Gazette, April 1978.

16 Professor Gandevia carried out the original medical examinations for VIC RAIL in 1957-1958.

17 Letter from Professor Gandevia to Mr J Frazer, 6 March, 1978. Note: A similar letter was sent at the same time to the Chief Medical Officer of VIC RAIL. 
pie, undated, pp. 58-59) As a consequence, the unions have resolved to disregard advice that may be given in the future by the IHD and to develop their own resources as well as to rely on the advice of such groups as the Workers' Health Resource Centre.

The ACAC became involved in this dispute from 18 March, 1978, some eight months after the initial bans were placed on all work on the Harris carriages at the Bendigo workshops. At this stage bans were also operating at Newport and Jolimont. Like many disputes that come before the ACAC a stalemate had been reached and as a consequence some options that were available at the beginning of the dispute were now no longer acceptable to the parties. Commissioner Walker did not underestimate the serious problem before him and well understood the feelings of the men involved. On the other hand he recognised that if a solution was not found quickly the dispute could escalate, causing severe disruption to the suburban rail network as well as bringing the issue into a wider arena. To this end the Commissioner attempted to deal only with the bans at Jolimont (Australian Conciliation and Arbitration Commission, 1978A, p. 47) but the unions insisted that the outcome must be applied simultaneously for all workshops where bans were in force.

At the arbitration conferences, considerable confusion surrounded what were appropriate asbestos standards to adopt and the type of protection necessary. Because of this, the unions were not prepared to state their position without referring back any new proposals to their medical advisers and ultimately their membership. Commissioner Walker however felt that the union officials were unnecessarily delaying proceedings and along with VIC RAIL applied considerable pressure on union officials to get the bans lifted. The union's response was the same, for example at the end of the second conference Mr Johnson representing the AMWSU stated:

If you are seeking an assurance from me, you will be disappointed. We look at the

situation on the basis of merit with our people and the case you are talking about

involves people who have not been adequately consulted and as a consequence they are going their own way .... We are not going to lord over our people. (Australian

Conciliation and Arbitration Commission, 1978A, p. 50)

A compulsory conference was then called for 31 March, 1978. Prior to this meeting the Jolimont Shop Committee passed a motion expressing concern at the undue pressure being placed upon their union officials to drop the bans, when little if any pressure was being brought to bear on VIC RAIL to accept the proposals put forward by the unions. This had little effect as Commissioner Walker in his opening remarks stated:

I made my position quite clear, that I was not satisfied with the negative replies that

I had received (from the unions) ... a far as I am concerned this matter has to be re-

solved. (Australian Conciliation and Arbitration Commission, 1978B, p. 55)

In an attempt to get the men to lift the bans the Commissioner had scheduled the conference to be held at the Jolimont workshops, summoning members of the shop committee but not notifying the ARU, ETU and AMWSU officials. The unions saw his action as a manoeuvre by which he hoped to get the workers on the job to adopt a more moderate and conciliatory posture and so split them away from the union leadership and their medical advisers. Although a resolution was finally achieved at this conference it left a feeling amongst the union officials that the Commissioner was preoccupied with settling a dispute rather than with equity or the welfare of the men on the job. These events have caused the unions involved to question whether the ACAC is the most appropriate forum for the resolution of health problems.

Clearly this dispute has led to doubts being raised about the roles of the IHD and the ACAC in industrial health matters, although on the positive side its influence can be seen in two subsequent events. In response to the Broadband programme and the ensuing VIC RAIL dispute, the Victorian Government in December 1978 gazetted the Asbestos Regulations (Labour and Industry (Asbestos) Regulations, 1978). Without going into the processes and influences in the development of these regulations, ${ }^{18}$ it is interesting to note 18 For a full report see Gillespie, R. (1980). 
that the standard adopted was that proposed by the BOHS in 1969 and occurred some seven years after Queensland's initial asbestos rules. It has been the subject of much criticism, in the main because those actually at risk, namely the workers, were not involved in the decision and was based solely on the risk of contracting asbestosis. The problem of lung cancer or mesothelioma was not considered.

Finally, in February 1979 the Federated Engine Drivers and Firemens' Association placed a ban on the handling of asbestos-related products at the Hazelwood Power Station in the Latrobe Valley. The SECV wishing to avoid the problems witnessed in the VIC RAIL dispute of a year earlier responded by setting up a joint management-union task force. This task force officially established in April, 1979 and comprising four union and three management representatives was charged with the responsibility of developing policies and programmes aimed at the containment and removal of asbestos products, guidelines for working in contaminated areas and worker education. The task force has now issued three reports $^{19}$ and has demonstrated an alternative means of approaching problems of mutual concern. The evidence to date (Operations Group Asbestos Task Force, 1980) indicates considerable progress has been made in an industry that has made extensive use of asbestosbased products.

\section{References}

Australian Conciliation and Arbitration Commission (1978A), Transcript of proceedings, 23 March, C No. 405.

Australian Conciliation and Arbitration Commission (1978B), Transcript of proceedings, 31 March, C No. 405.

Doll, R. (1955) Mortality from lung cancer in asbestos workers, British journal of industrial medicine, 12:81-86.

Dreitzel, H.P. (ed) (1971), The social organisation of health, New York, Macmillan.

Gillespie, R. (undated), Risk assessment in occupational health - the asbestos standard, University of Melbourne, unpublished paper.

Gillespie, R. (1980), Victorian asbestos regulations - a health hazard, Australian safety news. January-February.

Gilmer, B. (1971), Industrial and organisational psychology, New York, McGraw Hill. Gunningham, N. (1978), Asbestos hazards and legal regulation, Legal services bulletin, 3, April: $46-49$.

International Agency for Research on Cancer (1977), LARD monographs on the carcinogenic risk of chemicals to man: V14 asbestos, Lyon.

Labour and Industry (Asbestos) Regulations, (1978) Statutory rules, 1978, No. 435.

Lowrance, W.W. (1976), Of acceptable risk, California, Kaufman.

Merwether, E.R.A. and C.W. Price (1930), Report of the effects of asbestos dust on the lungs and dust supressors in the asbestos industry, London, HMSO.

Morgan, K.C. (1975), Occupational lung diseases, Philadelphia, Saunders.

National Health and Medical Research Council (Australia) (undated), The medical aspects of the effects of the inhalation of asbestos.

Operations Group Asbestos Taskforce No. 2, Progress report, February 1980.

Peacock, M. (1978), Asbestos: work as a health hazard, Sydney, Australian Broadcasting Commission.

Rosato, D.V. (1959), Asbestos: its industrial application, New York, Reinhold.

Victorian parliamentary proceedings, (Hansard), Legislative Assembly, 16 March 1978. Wagner, J.C. (1960), Diffuse pleural mesothelioma and asbestos exposure in the North Western Cape Province, British journal of industrial medicine, 17:260-271.

Workers' Health Centre (undated), Hazard report: assessment of potential asbestos hazard, Melbourne.

19 June 1979. July October 1979 and February 1980. 